\title{
Chemistry and spectroscopy of vanadium in VAPO-5 molecular sieves
}

\author{
Bert M. Weckhuysen, Ina P. Vannijvel, and Robert A. Schoonheydt \\ Centrum voor Oppervlaktechemie en Katalyse, Heverlee, Belgium
}

\begin{abstract}
VAPO-5 molecular sieves were synthesized hydrothermally starting with different vanadium, phosphorus, and template contents and with different templates as a function of time. The crystallization process was followed by $\mathrm{X}$-ray diffraction and scanning electron microscopy; the coordination of vanadium was investigated by diffuse reflectance spectroscopy (d.r.s.) and electron spin resonance (e.s.r.). In the gels, vanadium is present as an octahedral ion and can be washed off easily. The crystallization process is retarded by increasing the vanadium content and gel $(V+A I) / P$ ratios different from 1 . Good crystalline materials were obtained by using tripropylamine, triethylamine, and tetrapropylammoniumhydroxide as template and synthesis times between 48 and $120 \mathrm{~h}$. In the as-synthesized samples, isolated (pseudo-loctahedral $\mathrm{V}^{4+}$ is detected by e.s.r. and d.r.s. This vanadium is accessible by ammonia and comprises only $10 \%$ of the total vanadium content. Upon calcination, $\mathrm{V}^{4+}$ ions are oxidized to tetrahedral $\mathrm{V}^{5+}$, which can only be reduced partially to $\mathrm{V}^{4+}$. On this basis, no unambiguous evidence is found for isomorphous substituted vanadium in AIPO-5 molecular sieves.
\end{abstract}

Keywords: VAPO-5; isomorphous substitution; microporous aluminophosphates; synthesis; d.s.r.; e.s.r.

\section{INTRODUCTION}

Metal-substituted aluminophosphate molecular sieves (MeAPOs) possess interesting catalytic properties; this topic has been reviewed by Bellussi and Rigutto. ${ }^{1}$ CoAPO-5s are active in the autoxidation of $p$-cresol and cyclohexane, ${ }^{2-4}$ whereas CrAPO-5 catalysts oxidize secondary alcohols. ${ }^{5}$ VAPO-5 molecular sieves catalyze the ammoxidation of alkanes, epoxidation of alkenes and allylic alcohols, and oxidation of aromatic compounds. ${ }^{6-9}$

The isomorphous substitution of these metal ions $(\mathrm{Co}, \mathrm{Cr}$, and $\mathrm{V}$ ) in crystalline aluminophosphates is a matter of debate. ${ }^{1}$ In CoAPO-5s, tetrahedral $\mathrm{Co}^{2+}$ substitutes for $\mathrm{Al}^{3+}$, at least at low cobalt loadings; and, depending on the synthesis conditions, CoAPO-5 and CoAPO-34 can be obtained. ${ }^{10-12}$ As synthesized CrAPO-5 crystals possess only octahedral $\mathrm{Cr}^{3+}$, indicating no isomorphous substitution, ${ }^{13}$ whereas VAPO-5 molecular sieves contain isolated square pyrimidal $\mathrm{V}^{4+}$ and oxidic $\mathrm{V}\left(\mathrm{V}_{2} \mathrm{O}_{5}\right.$-like phase) ${ }^{6}{ }^{6}$ According to Montes et al. ${ }^{7}$ and Jhung et al., ${ }^{8}$ substitutes for $\mathrm{P}^{5+}$; Rigutto and van Bekkum ${ }^{6}$ suggested the replacement of $\mathrm{Al}^{3+}$ by $\mathrm{V}^{4+}$. Two questions remain unsolved. (1) Is vanadium substituting for phosphorus or aluminum and to what extent? (2) What is the effect of the synthesis conditions on the coordination and oxidation state of vanadium?

Address reprint requests to Dr. Weckhuysen at the Centrum voor Oppervlaktechemie en Katalyse, K.U. Leuven, Kardinaal Mercierlaan 92, B-3001 Heverlee, Belgium.

Received 11 January 1995; accepted 8 March 1995
These issues can only be solved by a systematic study of the synthesis process and of the crystalline materials by a combination of characterization techniques. In the present study, we have synthesized series of VAPO-5 molecular sieves with increasing vanadium, phosphorus, and template contents. The effects of synthesis time and template were studied by $\mathrm{X}$-ray diffraction (XRD) and scanning electron microscopy (SEM). The coordination chemistry of vanadium was studied by a combination of electron spin resonance (e.s.r.) and diffuse reflectance spectroscopy (d.r.s.) of the initial gels and of the assynthesized, calcined and reduced samples.

\section{EXPERIMENTAL}

\section{Synthesis procedure}

VAPO-5 was synthesized following a modified method of Flanigen et al. ${ }^{14}$ Vanadyl(IV) sulfate (Fluka) was added to a solution of $\mathrm{H}_{3} \mathrm{PO}_{4}$ (85 wt\% solution in water; pro analysis, Janssen Chimica) and bidistilled water under stirring until complete dissolution. Pseudo-boehmite (Capatal alumina, 70\% $\mathrm{Al}_{2} \mathrm{O}_{3}$ and $30 \% \mathrm{H}_{2} \mathrm{O}$; Vista) was added under stirring, followed by the dropwise addition of triethylamine (99\%, Janssen Chimica). The reaction mixture was prepared in an ice bath at $273 \mathrm{~K}$. The obtained homogeneous gel was stirred for $1 \mathrm{~h}$ and inserted in a Teflon-lined autoclave. The synthesis was performed at $448 \mathrm{~K}$. After synthesis, the material was 
washed three times with distilled water and dried at $333 \mathrm{~K}$ for $24 \mathrm{~h}$.

Five series of VAPO- 5 samples were prepared: A samples (as a function of vanadium content); B samples (as a function of synthesis time); C samples (as a function of template content); D samples (as a function of phosphorus content); and $\mathrm{E}$ samples (as a function of the template molecule). The A, B, C, and $D$ samples were prepared with triethylamine; the $E$ samples were synthesized with different template molecules. The synthesis conditions, notations, and gel compositions of all these samples are summarized in Table 1. A reference sample was prepared by impregnation of AlPO-5 with $\mathrm{VOSO}_{4}\left(\mathrm{~V}^{4}+/ \mathrm{AlPO}-5\right)$.

\section{Pretreatments and techniques}

The samples were granulated, and the size fraction $0.25-0.40 \mathrm{~mm}$ was loaded in a quartz flow cell with Suprasil windows for d.r.s. and a side arm for e.s.r. measurements. e.s.r. and d.r.s. were taken from the as-synthesized samples, after drying in $\mathrm{He}$ at $70^{\circ} \mathrm{C}$, after calcination, reduction, and recalcination; and from vacuum-treated samples. The d.r.s. spectra were measured with a u.v.-vis-n.i.r. Cary 5 spectrometer in the range $200-2,500 \mathrm{~nm}$ and against a Halon white standard. The spectra were converted to the Kubelka-Munk function and plotted as a function of wavenumbers after subtraction of a baseline. e.s.r. spectra were taken in the range of $120-370 \mathrm{~K}$ using a Bruker ESP300E equipment in X-band at a microwave power of $200 \mu \mathrm{W}$ with a double rectangular TE104 mode cavity. The spectra were simulated by a program, based on matrix diagonalization and second-order perturbation for superhyperfine splitting, developed by Mabbs and Collison. ${ }^{15}$ Quantitation of $\mathrm{V}$ in the e.s.r. spectra was performed after double integration using a $\mathrm{Cu}(\mathrm{acac})_{2}$ (Strem Chemicals) diluted in $\mathrm{KCl}$ standard. Calcination and recalcination (after reduction) were performed at $823 \mathrm{~K}$ for $12 \mathrm{~h}$ with an oxygen flow rate of $3,600 \mathrm{ml} / \mathrm{h}$; reduction was done for $30 \mathrm{~min}$ with a CO flow rate of $1,800 \mathrm{ml} / \mathrm{h}$ at $573 \mathrm{~K}$. d.r.s. spectra were also taken from the wet precursor gels of the A-type samples as such and after successive centrifugations $(20 \mathrm{~min}, 5,000$ rounds/ $\mathrm{min})$. Vacuum pretreatments were done at $2 \times 10^{-3}$ $\mathrm{Pa}$ at 298 and $473 \mathrm{~K}$ overnight. Some samples were treated after drying at $70^{\circ} \mathrm{C}$ with ammonia for $15 \mathrm{~min}$ at $423 \mathrm{~K}$. Powder XRD patterns of the as-synthesized, calcined, and recalcined samples were recorded with a Philips PW 1012/30 powder diffractometer. SEM on the as-synthesized samples was performed on a Jeol Superprobe 733 .

\section{RESULTS}

\section{Spectroscopy of the wet precursor gels}

The precursor gels were light blue or blue, depending on the $\mathrm{V}$ content. The coordination and retention of $\mathrm{V}$ in these gels were investigated by d.r.s., as shown in Figure 1. The retention of $\mathrm{V}$ was tested by washing the gel with bidistilled water followed by centrifugation. The spectra of a fresh gel showed at least five $d-d$ transitions of $\mathrm{V}^{4+}$ in the region $10,000-20,000 \mathrm{~cm}^{-1}$. After one washing, most of the $\mathrm{V}$ was removed; by washing further the amount removed was rather small. The residual $\mathrm{V}^{4+}$ spectrum contained three broad bands, the relative intensities of which were different from those of the initial spectrum. This suggests the presence of at least two $\mathrm{V}^{4+}$ species; both are, however (pseudo-) octahedral. ${ }^{16}$

\section{Synthesis of VAPO-5}

Figure 2 shows the XRD diffractograms of the A samples (see Table 1) with increasing $\mathrm{V}$ content. The spectra are typical for AlPO-5, but the relative intensities of the peaks in Figure 2 (especially between 19.5 $<2 \theta<22.5)$ depend on the $\mathrm{V}$ content. The XRD diffractogram of the A- 0.08 sample contains four extra peaks near $13,18,38$, and $44^{\circ}$, indicative of a second crystalline phase. Furthermore, with increasing $\mathrm{V}$ content, the formation of VAPO-5 from pseudo-boehmite required a longer synthesis time. This is evidenced by the weak XRD line intensities of A-0.08-48 h in Figure 2. Table 2 summarizes the composition of the initial gel and the corresponding

Table 1 Overview of the notations, synthesis conditions, and gel compositions of the samples

\begin{tabular}{|c|c|c|c|c|c|c|c|}
\hline \multirow[b]{2}{*}{ Sample name } & \multicolumn{6}{|c|}{ Gel composition: $r R \cdot\left(\mathrm{V}_{x} \mathrm{Al}_{y} \mathrm{P}_{z}\right) \mathrm{O}_{4} \cdot 16.7 \mathrm{H}_{2} \mathrm{O}$} & \multirow[b]{2}{*}{ Synthesis time (h) } \\
\hline & $\mathbf{r}$ & $\mathbf{R}$ & $x$ & $y$ & $z$ & pH & \\
\hline $\begin{array}{l}\text { A-0.01 } \\
\text { A-0.02 } \\
\text { A-0.04 } \\
\text { A-0.08 } \\
\text { B-0.02 } \\
C-1 \\
C-2 \\
C-3 \\
D-1 \\
\text { D-2 } \\
\text { E-Pr }{ }_{3} \text { N } \\
\text { E-Pr } \mathbf{N H} \\
\text { E-TMAOH } \\
\text { E-TPAOH }\end{array}$ & $\begin{array}{l}0.74 \\
0.74 \\
0.74 \\
0.74 \\
0.74 \\
0.5 \\
1.0 \\
1.25 \\
0.74 \\
0.74 \\
0.74 \\
0.74 \\
0.74 \\
0.74\end{array}$ & $\begin{array}{l}\mathrm{Et}_{3} \mathrm{~N} \\
\mathrm{Et}_{3} \mathrm{~N} \\
\mathrm{Et}_{3} \mathrm{~N} \\
\mathrm{Et}_{3} \mathrm{~N} \\
\mathrm{Et}_{3} \mathrm{~N} \\
\mathrm{Et}_{3} \mathrm{~N} \\
\mathrm{Et}_{3} \mathrm{~N} \\
\mathrm{Et}_{3} \mathrm{~N} \\
\mathrm{Et}_{3} \mathrm{~N} \\
\mathrm{Et}_{3} \mathrm{~N} \\
\mathrm{Pr}_{3} \mathrm{~N} \\
\mathrm{Pr}_{2} \mathrm{NH} \\
\mathrm{TMAOH}^{\mathrm{M}} \mathrm{OH} \\
\text { TPAOH }\end{array}$ & $\begin{array}{l}0.01 \\
0.02 \\
0.04 \\
0.08 \\
0.02 \\
0.02 \\
0.02 \\
0.02 \\
0.02 \\
0.02 \\
0.02 \\
0.02 \\
0.02 \\
0.02\end{array}$ & $\begin{array}{l}0.99 \\
0.98 \\
0.96 \\
0.92 \\
0.98 \\
0.98 \\
0.98 \\
0.98 \\
0.98 \\
0.98 \\
0.98 \\
0.98 \\
0.98 \\
0.98\end{array}$ & $\begin{array}{l}1 \\
1 \\
1 \\
1 \\
1 \\
1 \\
1 \\
1 \\
0.72 \\
1.67 \\
1 \\
1 \\
1 \\
1\end{array}$ & $\begin{array}{l}3.76 \\
4.26 \\
3.70 \\
2.90 \\
4.26 \\
3.03 \\
6.06 \\
6.75 \\
5.84 \\
2.30 \\
5.76 \\
3.49 \\
1.99 \\
2.99\end{array}$ & $\begin{array}{l}2,24 \\
48 \\
48 \\
48 \\
2,4,24,48,72,96,120,144,168 \\
24,72 \\
24,72 \\
24,72 \\
72 \\
2,24,72 \\
24,72 \\
24,72 \\
24,72 \\
24,72\end{array}$ \\
\hline
\end{tabular}




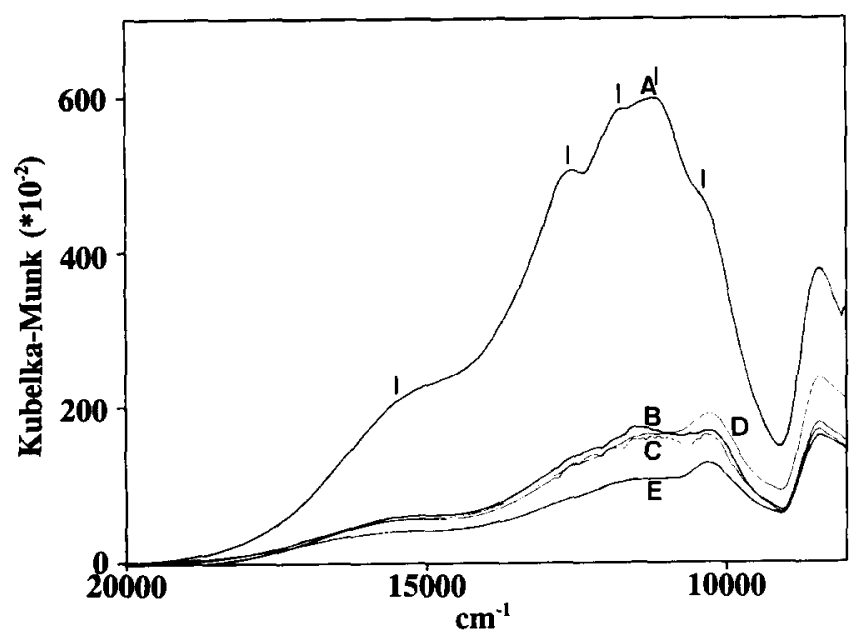

Figure 1 d.r.s. spectra of the wet precursor gel (A-0.02 sample) (A) and of the gel after one (B), two (C), three (D) and four (E) washings.

chemical analysis of the as-synthesized VAPO-5 samples. At low $\mathrm{V}$ content, the $(\mathrm{V}+\mathrm{Al}) / \mathrm{P}$ ratio was close to 1 , whereas at higher loadings it deviated from 1 . This suggests excess $\mathrm{V}$ and/or Al in VAPO-5, the excess increasing with amount of $\mathrm{V}$.

With the B samples, the synthesis was followed as a function of time, changing between 2 and $168 \mathrm{~h}$. Samples B-0.02-2 $h$ and B-0.02-4 $h$ are amorphous, and only after $24 \mathrm{~h}$, could the typical XRD lines of AlPO- 5 be detected. No crystalline phase other than VAPO-5 appeared, even after $168 \mathrm{~h}$. The optimal

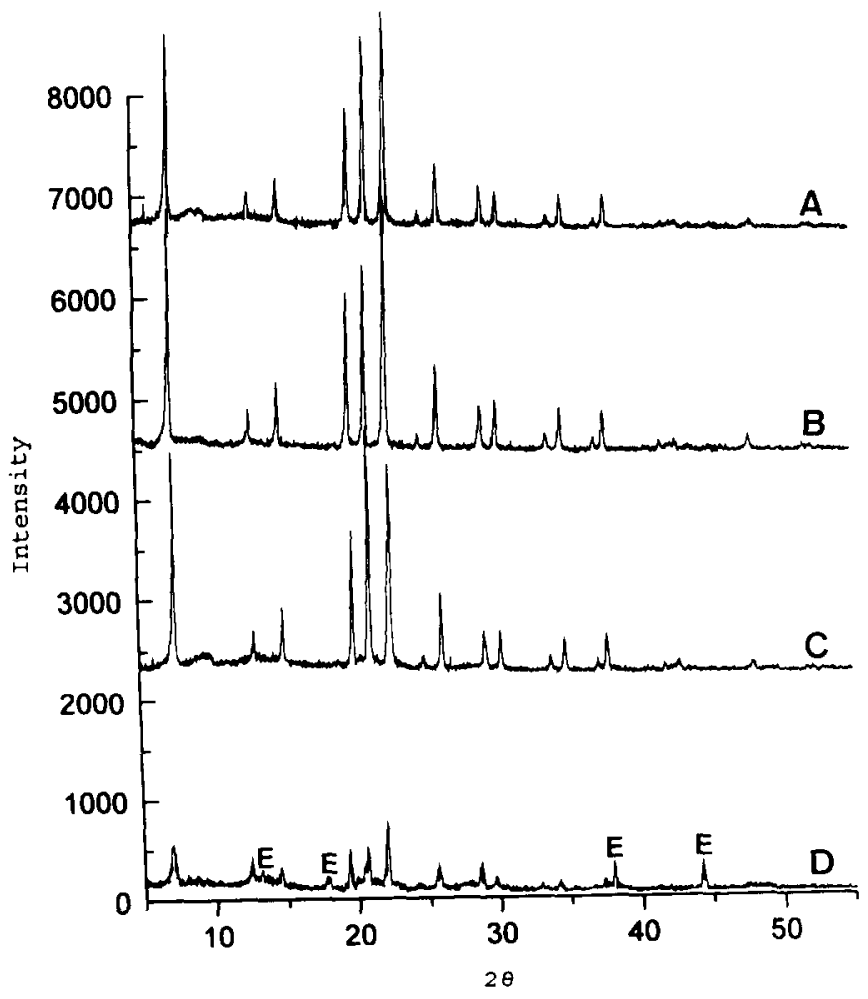

Figure $2 X R D$ diffractograms of the $A$ samples as function of the vanadium content: (A) $A-0.01-24 h$; (B) $A-0.02-48 h$; (C) $A-0.04-48 h$; (D) A-0.08-48 h.
Table 2 Chemical analysis of as-synthesized VAPO- 5 materials

\begin{tabular}{lcc}
\hline Sample name & $\begin{array}{c}\text { Vanadium content } \\
\text { in initial gel }\end{array}$ & $\begin{array}{c}(\mathrm{V}+\text { Al)/P ratio of the } \\
\text { as-synthesized } \\
\text { materials }\end{array}$ \\
\hline VAPO-0.01-24 h & 0.01 & 1.03 \\
VAPO-0.02-48 h & 0.02 & 1.09 \\
VAPO-0.04-48 h & 0.04 & 1.68 \\
VAPO-0.08-48 h & 0.08 & 1.29 \\
\hline
\end{tabular}

synthesis time was between 48 and $120 \mathrm{~h}$. The B-0.02$120 \mathrm{~h}$ sample, as shown in the SEM in Figure 3, contained two different kinds of crystals: hexagonal, with a size between 5 and $10 \mu \mathrm{m}$, and needle-shaped, with a length of 2-10 $\mu \mathrm{m}$. The amount of needles increased with decreasing synthesis time. The crystals from the B-0.02-168 $\mathrm{h}$ sample formed agglomerates. The hexagonal and needle-shaped structures were still present.

In other experiments, the influence of the template (R) content and phosphorus content on the synthesis of VAPO-5 was investigated. The optimal template content for the $\mathrm{C}$ samples (see Table 1) synthesized for $24 \mathrm{~h}$ was $0.5 \mathrm{Et}_{3} \mathrm{~N} /\left[(\mathrm{Al}, \mathrm{V}) \mathrm{O}_{2}+\mathrm{PO}_{2}\right]$. Above 0.74 $\mathrm{Et}_{3} \mathrm{~N} /\left[(\mathrm{Al}, \mathrm{V}) \mathrm{O}_{2}+\mathrm{PO}_{2}\right]$, additional lines appeared in the XRD diffractograms. After a synthesis time of 72 $h$, the typical AlPO-5 pattern was observed, whatever the template content. The phosphorus amount seems critical for the synthesis of VAPO-5. With an excess of phosphorus $[(\mathrm{Al}+\mathrm{V}) / \mathrm{P}<1]$, VAPO-5 was synthe-

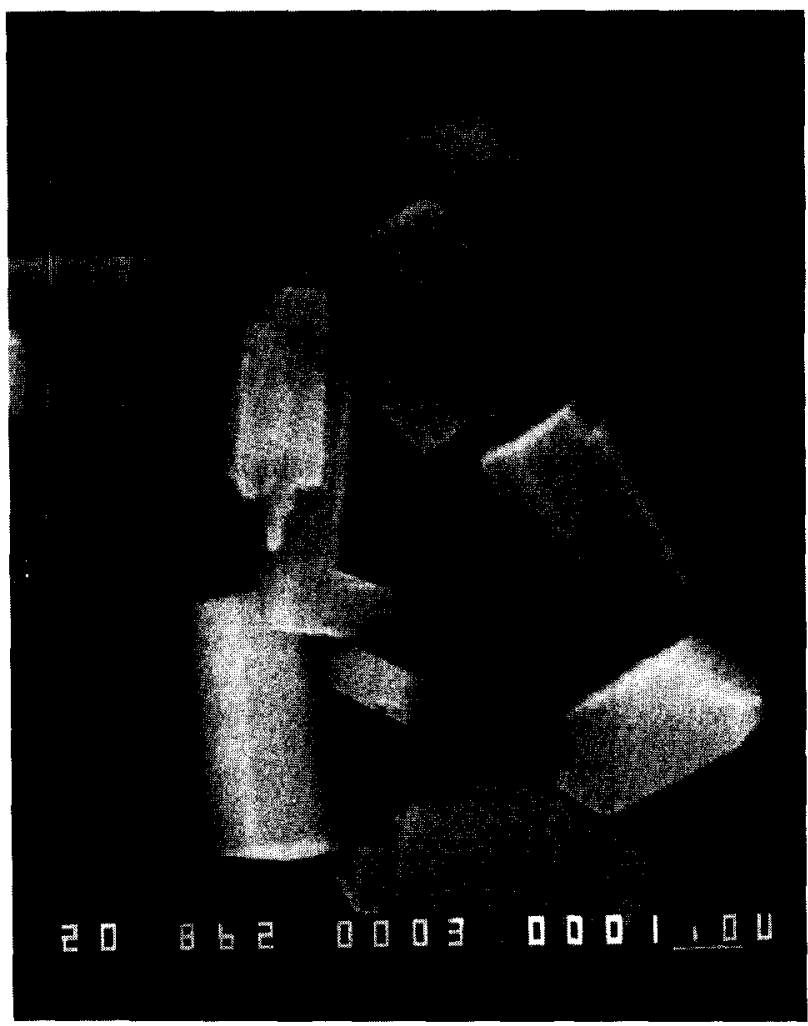

Figure 3 SEM of the B-0.02-120 h sample. 
sized initially, but at longer synthesis time (24 or $72 \mathrm{~h}$ ) other crystalline phases were formed. When the $\mathrm{Al}$ $+\mathrm{V}) / \mathrm{P}$ ratio largely exceeded 1 , only a few crystals were formed, even after $72 \mathrm{~h}$ of synthesis.

The XRD diffractograms for VAPO- 5 samples synthesized with different template molecules showed a pure AFI phase for tripropylamine and triethylamine after $24 \mathrm{~h}$; with tetrapropylammoniumhydroxide a VAPO-5 phase was formed after $72 \mathrm{~h}$ of synthesis. With tetramethylammoniumhydroxide and dipropylamine, no pure VAPO-5 samples could be obtained.

\section{Chemistry and spectroscopy of VAPO-5}

\section{As-synthesized VAPO-5}

The e.s.r. spectra of VAPO- 5 as a function of the vanadium loading are shown in Figure 4 . The spectra are characterized by two axially symmetric signals with hyperfine splitting. Such spectra are typical for vanadium(IV), with $d^{1}$ configuration and $I=7 / 2$, and are usually designated as $S_{1}$ and $S_{2}$ signals. ${ }^{6,7}$ These signals possess slightly different $g$ and A values (see further). At higher $V$ contents an additional broad signal is formed with $g$ around 2. At low loadings, the total integrated intensity of the spectrum follows the Curie-Weiss law in the measured temperature range of $120-370 \mathrm{~K}$. This is not the case at high $\mathrm{V}$ content. This observation supports the idea that $S_{1}$ and $S_{2}$ are due to magnetically isolated $\mathrm{V}^{4+}$ ions, whereas the broad signals can be assigned as oxidic V. In any case, the calculated spin densities correspond to less than $10 \%$ of the $\mathrm{V}$, independent of the $\mathrm{V}$ content.

Figure 5 shows a simulation of the e.s.r. spectrum of the A-0.01 sample, which is performed by using a

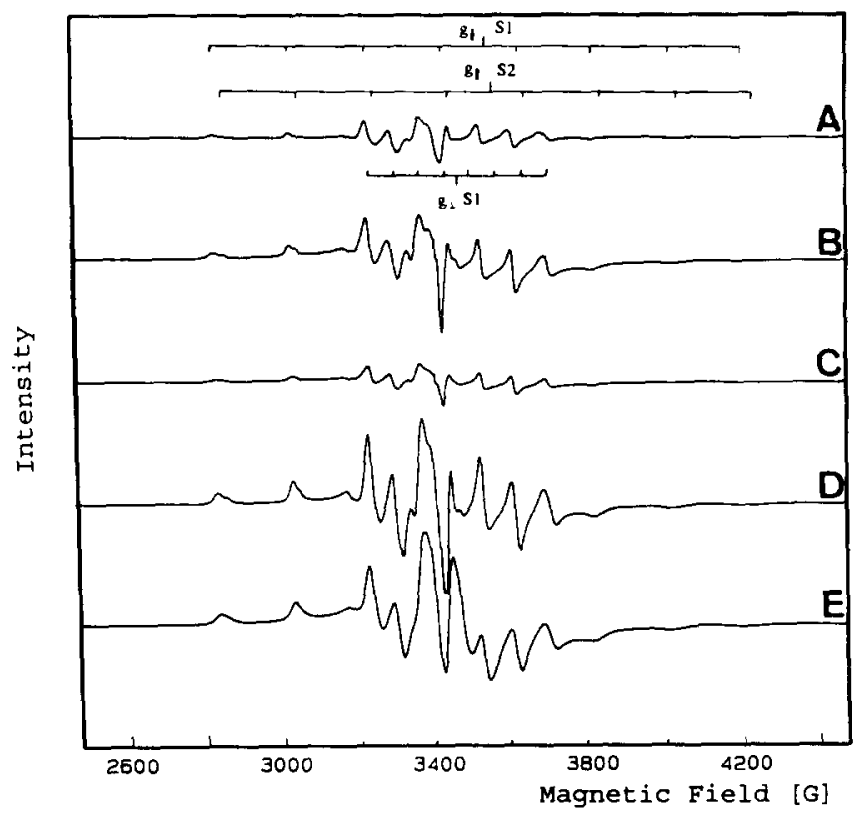

Figure 4 e.s.r. spectra of the $A$ samples as function of the vanadium content: (A) A-0.01-24 h measured at $120 \mathrm{~K}$; (B) A-0.02$48 \mathrm{~h}$ measured at $120 \mathrm{~K}$; (C) A-0.02-48 h measured at $300 \mathrm{~K}$; (D) $\mathrm{A}-0.04-48 \mathrm{~h}$ measured at $120 \mathrm{~K}$; and (E) A-0.08-48 $\mathrm{h}$ measured at $120 \mathrm{~K}$. rhombic symmetric Hamiltonian with hyperfine splitting. The procedure consists of three steps: (1) a separate simulation of the $S_{1}$ and $S_{2}$ signals; (2) a summation of both simulated spectra with appropriate weight factors; and (3) comparison with the experimental spectra and possible reevaluation of the starting variables and reiteration. It can be deduced from Figure 5 that a good resemblance is obtained between the experimental and calculated spectrum. The obtained $g$ and A values are summarized in Table 4 and compared with some literature data. The spectral parameters of $S_{1}$ and $S_{2}$ are typical for a distorted octahedral $\mathrm{V}^{4+}$.

The corresponding d.r.s. spectrum (Figure 6) shows two absorption bands in the $10,000-20,000 \mathrm{~cm}^{-1}$ region: at $13,100 \mathrm{~cm}^{-1}$ with a low field shoulder and at $16,500 \mathrm{~cm}^{-1}$. The intensity increases with increasing $\mathrm{V}$ content. These values can be compared with absorption bands of reference compounds summarized in Table 3. The observed absorptions are typical for (pseudo-) octahedral vanadyl species.

The d.r.s. and e.s.r. spectra are similar for the syntheses performed as a function of time. The e.s.r. intensity attains its maximum after $72 \mathrm{~h}$ of synthesis, whereas the d.r.s. bands decrease with increasing synthesis time. This means that different $\mathrm{V}$ species are probed by these techniques. No systematic influence of the template content on the spectroscopic features could be observed. However, the kind of template molecule strongly influences the e.s.r.-spectra: with $\operatorname{Pr}_{3} \mathrm{~N}$ and $\mathrm{Et}_{3} \mathrm{~N}$ the typical $\mathrm{S}_{1}$ and $\mathrm{S}_{2}$ signals are formed, whereas for the other templates only the $S_{1}$ signal superposed on a broad signal is detected.

\section{Oxidized and reduced VAPO-5}

The e.s.r. spectra as a function of treatment conditions are given in Figure $7 \mathrm{~A}$. After helium treatment at $70^{\circ} \mathrm{C}$, the $g$ and $A$ values change slightly, and the distinction between $S_{1}$ and $S_{2}$ is more clearly resolved (see Table 4). Oxygen treatment at $110^{\circ} \mathrm{C}$ changes only color, whereas the spectra remain unchanged. By calcination at $550^{\circ} \mathrm{C}$, the sample is yellow, and the e.s.r. signal has almost completely disappeared. After $\mathrm{CO}$ reduction, the color changes to purple-gray, and the $S_{1}$ and $S_{2}$ signals are reestablished; however, the relative intensity of $S_{1}$ is lower than that of $S_{2}$. The measured spin density is then about $60 \%$ of the original value before calcination (Figure $7 B$ ). Simulation of the e.s.r. spectra of the reduced samples was possible by taking into account only signal $S_{2}$ and axial symmetry. The obtained $g$ and A values are given in Table 4. The parameters are typical for (pseudo-) octahedral $\mathrm{V}^{4+}$. Recalcination restores the situation after initial calcination.

The d.r.s. spectra remain unchanged after helium and oxygen treatment at 70 and $110^{\circ} \mathrm{C}$, respectively. After calcination at $550^{\circ} \mathrm{C}$ an intense band around $36,000 \mathrm{~cm}^{-1}$ appears (Figure 6) which is due to the $O$ $\rightarrow \mathrm{V}^{5+}\left(d^{0}, T_{\mathrm{d}}\right)$ charge transfer of tetrahedral $\mathrm{V}^{5+}$ (see Table 3). Reduction results in the disappearance of this band and the formation of a strong band at $12,400 \mathrm{~cm}^{-1}$ and a weak one around $16,500 \mathrm{~cm}^{-1}$. 

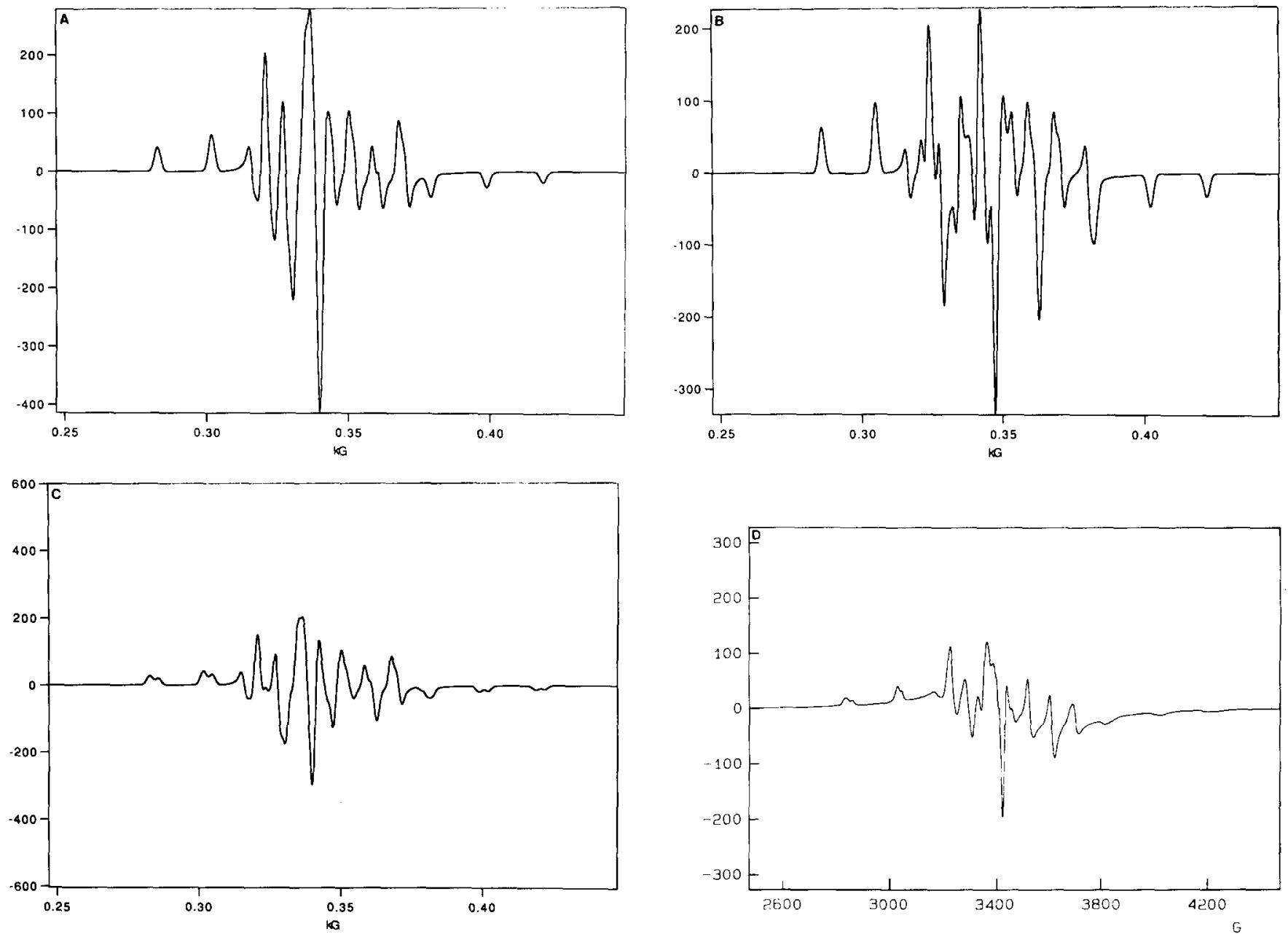

Figure 5 Simulation procedure of the e.s.r. spectrum of as-synthesized A-0.01 sample. (A), simulation of $S_{1} ;(B)$, simulation of $S_{2} ;(C)$ summation of simulated $S_{1}$ and $S_{2}$ (with $S=0.65 \cdot S_{1}+0.35 \cdot S_{2}$ ); and (D) the experimental e.s.r. spectrum.

The latter is reminiscent of the original pseudo-octahedral $\mathrm{V}^{4+}$. The former is probably also due to $\mathrm{V}^{4+}$.

Vacuum- and ammonia-treated VAPO-5

Vacuum treatment was performed at room tem-

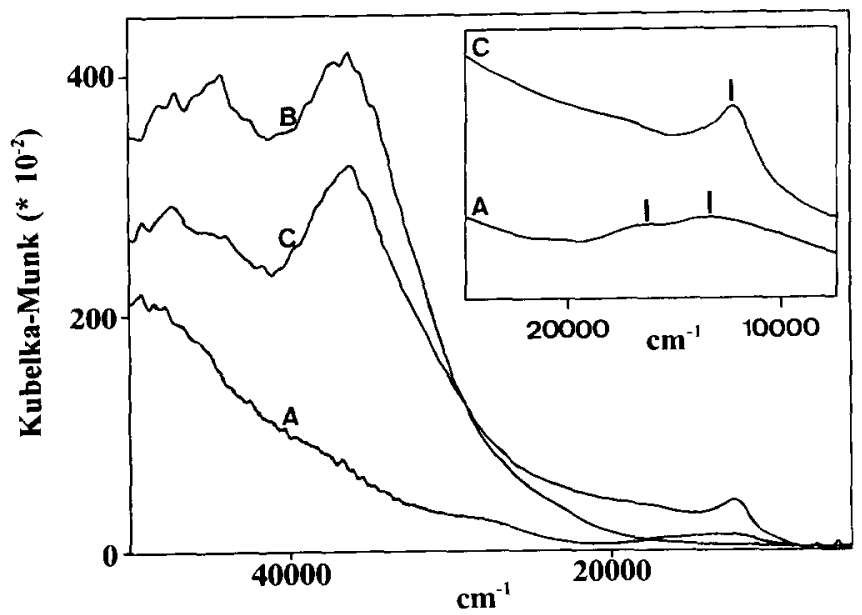

Figure 6 d.r.s. spectrum of the A-0.02-48 $h$ sample $(A)$ assynthesized; (B) calcined at $500^{\circ} \mathrm{C}$ in $\mathrm{O}_{2}$; and (C) reduced at $300^{\circ} \mathrm{C}$ in $\mathrm{CO}$. perature and $100^{\circ} \mathrm{C}$. The e.s.r. $S_{1}$ and $S_{2}$ do not change significantly, except that their intensities decrease upon heating. The d.r.s. spectra are unchanged up to a vacuum treatment at $100^{\circ} \mathrm{C}$ (not shown for brevity). Ammonia treatment at $150^{\circ} \mathrm{C}$ on as-synthesized samples results in the disappearance of the $S_{1}$ and $S_{2}$ signal, and a new octet signal becomes visible in e.s.r. (see Table 4); the d.r.s. spectra remain unchanged except for the overtones of $\mathrm{NH}$ at 6,300 $\mathrm{cm}^{-1}$.

\section{DISCUSSION}

This work is a systematic study of the synthesis of VAPO-5 molecular sieves, and the synthesized materials are spectroscopically characterized by a combination of d.r.s. and e.s.r.

\section{Synthesis of VAPO-5}

The optimum conditions of VAPO-5 are the same as those of AlPO-5, as far as nature and amount of template are concerned. ${ }^{17}$ At a constant synthesis temperature and time, the crystallinity of the products, as observed from the XRD patterns, decreases 
Table 3 d.r.s. absorption bands of some reference compounds $(15,18-20)$

\begin{tabular}{|c|c|c|}
\hline Reference compound & Absorption bands $\left(\mathrm{cm}^{-1}\right)$ & Assignment \\
\hline
\end{tabular}

with increasing $\mathrm{V}$ content. Thus, $\mathrm{V}$ retards the synthesis. As the $\mathrm{V}$ loading increases, the synthesis time increases. At $x=0.08$ no pure AFI phases can be obtained. Equally important for obtaining pure AFI phases is the $(\mathrm{V}+\mathrm{Al}) / \mathrm{P}$ ratio of 1 . Any deviation gives mixtures or phases or incomplete crystallinization. This suggests that, if $\mathrm{V}$ substitutes into the lattice, it will take the $\mathrm{Al}^{3+}$ site. This idea is in agreement with that of Rigutto and van Bekkum ${ }^{6}$ but not with Montes et al.

\section{Spectroscopy of VAPO-5}

As far as gel chemistry is concerned, most $\mathrm{V}=\mathrm{O}^{2+}$ is loosely bound to the synthesis gel. A small fraction only is bound as a pseudo-octahedral species. This is

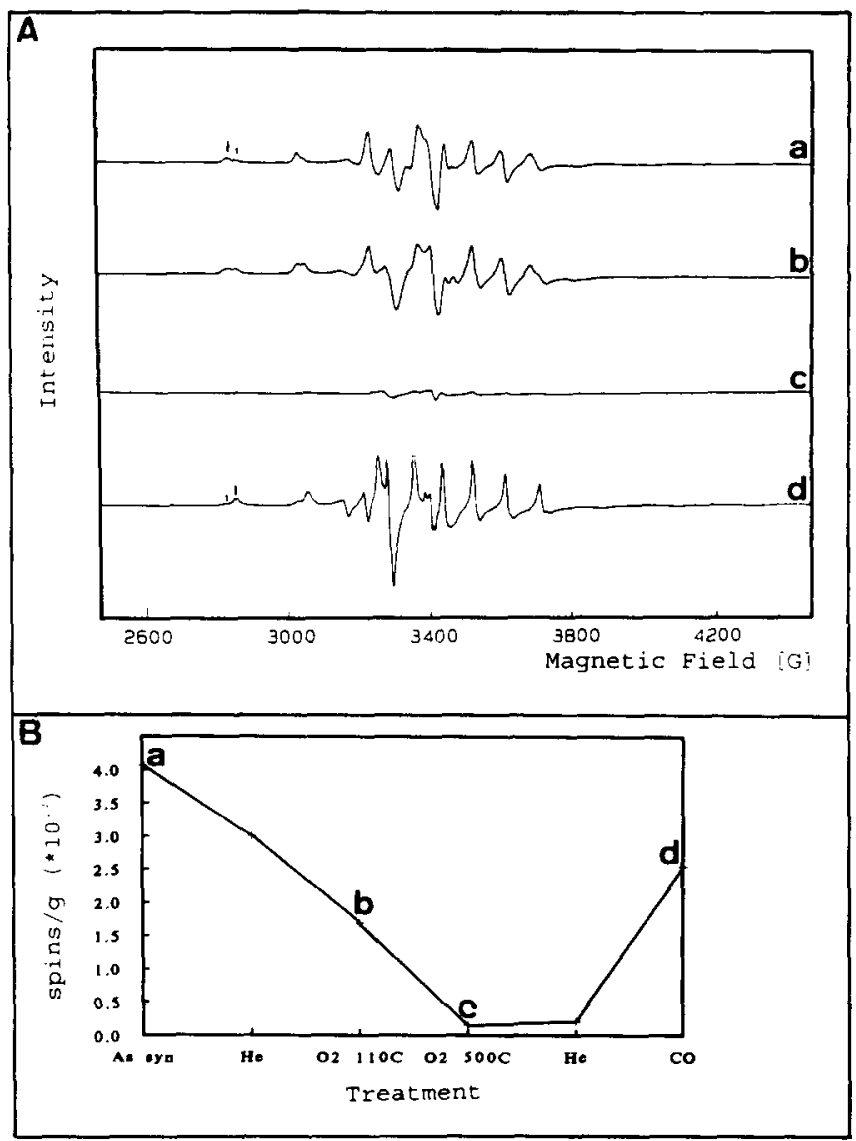

Figure 7 (A), e.s.r. spectra of the A-0.01 sample as function of pretreatment: (a) as-synthesized; (b) dried at $110^{\circ} \mathrm{C}$ in $\mathrm{O}_{2}$; (c) calcined at $500^{\circ} \mathrm{C}$ in $\mathrm{O}_{2}$; and (d) reduced at $300^{\circ} \mathrm{C}$ in $\mathrm{CO}$. (B), spin densities as function of pretreatment. analogous to the situation of $\mathrm{Co}^{2+} \cdot{ }^{12}$ In the assynthesized VAPO-5 V is present as $\mathrm{V}^{4+}$. No spectroscopic evidence is found for other oxidation states. d.r.s. and e.s.r. do give complementary information about this $\mathrm{V}^{4+}$. Thus, whereas the d.r.s. spectra are characteristic of the total $\mathrm{V}$ content, present as $\mathrm{V}^{4+}$, e.s.r. reveals the magnetically diluted fraction, which is less than $10 \%$ of the total $\mathrm{V}^{4+}$ content and is not resolved in the d.r.s. spectrum. Both d.r.s. and e.s.r. spectra are indicative for pseudo-octahedral $\mathrm{V}^{4+}$ with up to six oxygens in the first coordination sphere.

Three types of pseudo-octahedral $\mathrm{V}^{4+}$ exist: minor quantities giving the e.s.r. signals $S_{1}$ and $S_{2}$, and an extralattice oxidic phase characterized by the broad $g$ $=2$ signal. Although they make up at maximum $10 \%$ of the total $\mathrm{V}^{4+}$ content, it cannot be excluded that the weak $g=2$ signal is representative of the other $90 \%$ of $\mathrm{V}^{4+}$ too. If one assumes that this $90 \%$ is also present in the form of oxidic $\mathrm{V}^{4+}$ clusters of various sizes, then magnetic interactions among $\mathrm{V}^{4+}$ may account for the weakness of the signal at $110 \mathrm{~K}$. This also means that the majority of $\mathrm{V}^{\mathcal{A}}$ is extralattice and that the d.r.s. spectra are representative of oxidic $\mathrm{V}^{4+}$ clusters. $S_{1}$ and $S_{2}$ have been observed in other crystalline and amorphous materials ${ }^{21-27}$ (Table 4). In addition, the lack of spectroscopic features of tetrahedral $\mathrm{V}^{4+}$ excludes true isomorphous substitution. At best, $S_{1}$ and $S_{2}$ are atomically dispersed, pseudooctahedral $\mathrm{V}^{4+}$ species, anchored to the surface, most likely at an $\mathrm{Al}^{3+}$ site. Possible models have been proposed by Rigutto and van Bekkum, ${ }^{6}$ but others may be envisaged. Thus, $\mathrm{NH}_{3}$ interacts with the $\mathrm{V}^{4+}$ species giving the signals $S_{1}$ and $S_{2}$. This indicates that either they have a free coordination site, or $\mathrm{NH}_{3}$ substitutes for water in the coordination sphere. This is shown schematically in Figure 8. No change is observed in the d.r.s. spectrum, suggesting that $\mathrm{V}$ is present in extralattice clusters.

\section{Chemistry of VAPO-5}

Upon oxidation all $\mathrm{V}$ is recovered in the form of $\mathrm{V}^{5+}$ with the typical $\mathrm{O} \rightarrow \mathrm{V}^{5+}$ charge transfer band of $\mathrm{VO}_{4}{ }^{3-}$. Such a tetrahedral environment is typical for atomically dispersed $\mathrm{V}^{5+}$ and is also found for supported V catalysts. ${ }^{25-28}$ Therefore, its presence is not sufficient evidence for isomorphous substitution as claimed by Jhung et al. ${ }^{8} \mathrm{By} \mathrm{CO}$ reduction, (pseudo-)octahedral $\mathrm{V}^{4+}$ is partially regenerated (as a $\mathrm{S}_{2}$ signal), whereas the sharp absorption band at 12,500 $\mathrm{cm}^{-1}$ in d.r.s. is probably due to (pseudo-)octahedrally coordinated $\mathrm{V}^{2+}$ (Table 3 ). 
Table 4 e.s.r. parameters of VAPO-5 molecular sieves after different pretreatments and of some reference compounds

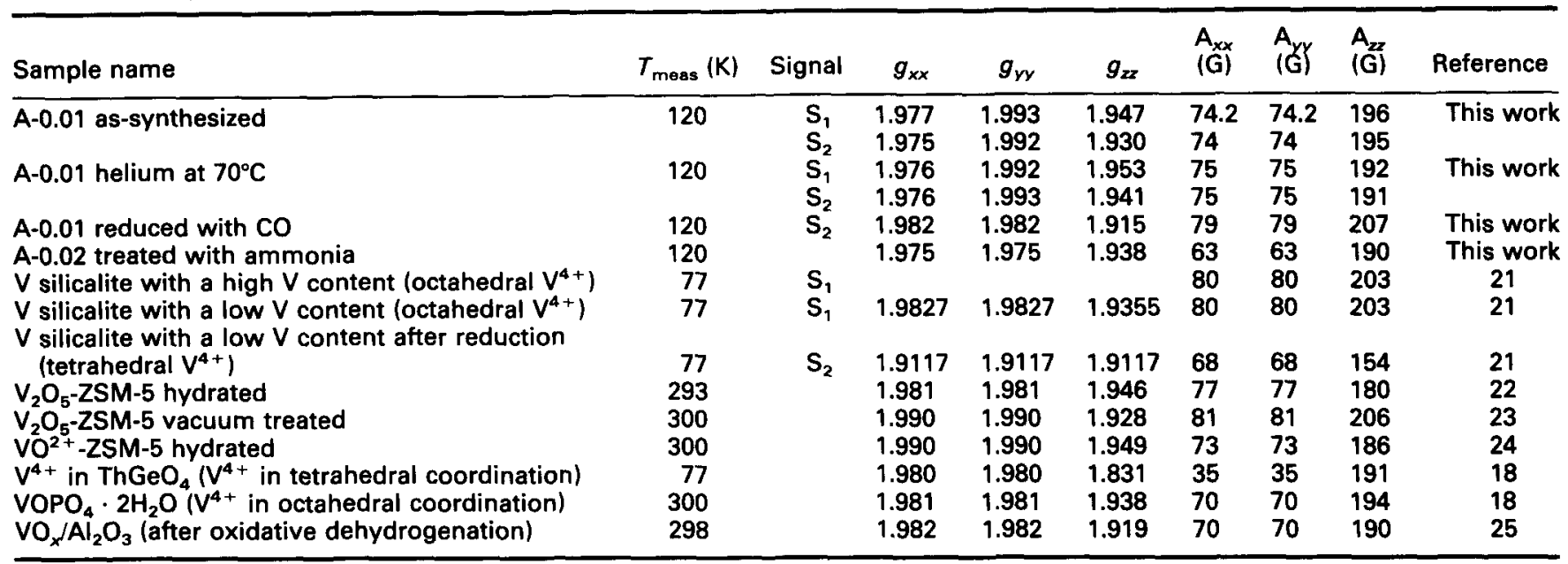

In summary, this study shows that independently of the synthesis time, template, phosphorus, and vanadium content, vanadium in VAPO-5 molecular sieves is present as isolated $\mathrm{V}^{4+}$ and oxidic $\mathrm{V}$. Under all conditions of the present investigation $\mathrm{V}$ is in (pseudo-)octahedral coordination. Calcination results in the formation of tetrahedral $\mathrm{V}^{5+}$, whereas reduction partially regenerates $\mathrm{V}^{4+}$ ions. No spectroscopic evidence is found for true isomorphous substitution of $\mathrm{V}^{4+}$ into the lattice of AlPO-5 molecular sieves, that is, $\mathrm{V}^{4+}$ tetrahedrally coordinated to four lattice oxygens.

\section{CONGLUSIONS}

Pure VAPO-5 molecular sieves can be synthesized hydrothermally starting with different $\mathrm{V}$ and template content and with different templates as a function of time. In the gels, $\mathrm{V}$ is present as an octahedral ion and can be largely washed off from the gel. The crystallization process is retarded by increasing the $\mathrm{V}$ content and gel $(\mathrm{V}+\mathrm{Al}) / \mathrm{P}$ ratios different from 1 . Good crystalline materials were obtained by using tripropylamine, triethylamine, and tetrapropylammoniumhydroxide as template and synthesis times between 48 and $120 \mathrm{~h}$. With e.s.r. only the atomically dispersed $\mathrm{V}^{4+}$ is visible; d.r.s. shows the total amount. Both spectroscopic techniques reveal that $\mathrm{V}$ is present as oxidic and/or anchored $\mathrm{V}^{4+}$ ion. Isolated, anchored $\mathrm{V}^{4+}$ is accessible by ammonia, indicating a free coordination site. $\mathrm{V}^{4+}$ is oxidized to $\mathrm{V}^{5+}$. This $\mathrm{V}^{5+}$ is reducible to $\mathrm{V}^{\mathrm{n}+}$ (with $n<5$ ). No unambiguous evi-

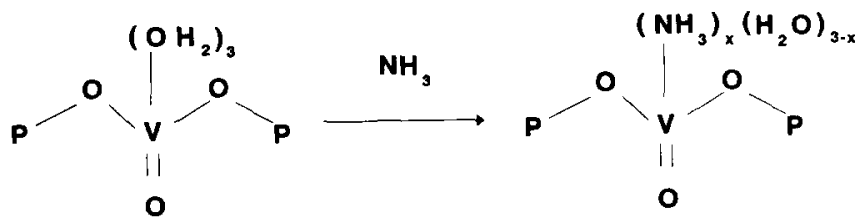

Figure 8 Proposed structure of the anchored vanadium species in VAPO-5 and the interaction with ammonia. dence is found for isomorphous substituted $\mathrm{V}$ in AlPO-5 molecular sieves.

\section{ACKNOWLEDGMENTS}

B.M.W. acknowledges the Belgian National Fund for Scientific Research (NFWO) for a grant as research assistant and for a travel grant to visit the University of Manchester (UK). The use of the e.s.r. simulation software of David Collison and Frank Mabbs (University of Manchester) and their advice are gratefully acknowledged. This work was supported financially by the Fonds voor Kollectief Fundamenteel Onderzoek (KFKO) Grant 2.0050 .93 and by the Geconcerteerde Onderzoeksacties (GOA/94/3) of the Flemish government.

\section{REFERENCES}

1 Bellussi, G. and Rigutto, M.S. Stud. Surf. Sci. Catal. 1994, 85, 177

2 Dakka, J. and Sheldon, R.A. Netherl. Pat. 9200968 (1992)

3 Peeters, M.P.J. PhD Thesis, University of Eindhoven, The Netherlands, 1993

4 Lin, S.S. and Weng, H.S. Appl. Catal. A 1993 105, 289

5 Chen, J.D., Dakka, J., Neeleman, E. and Sheldon, R.A. J. Chem. Soc. Chem. Commun. 1993, 1379

6 Rigutto, M.S. and van Bekkum, H. J. Mol. Catal. 1993, 81, 77

7 Montes, C., Davis, M.E., Murray, B. and Naryana, M. J. Phys. Chem. 1990, 94, 6425

8 Jhung, S.H., Uh, Y.S. and Chon, H. Appl. Catal. 1990, 62, 61

9 Miyamoto, A., Iwamoto, Y., Matsuda, Y. and Inui, T. Stud. Surf. Sci. Catal. 1989, 49B, 1233

10 Schoonheydt, R.A., de Vos, R., Pelgrims, J. and Leeman, H. Stud. Surf. Sci. Catal. 1989, 49A, 559

11 Iton, L.E., Choi, I., Desjardins, J.A. and Maroni, V.A. Zeolites $1989,9,535$

12 Uytterhoeven, M.G. and Schoonheydt, R.A. Microporous Mater. 1994, 3, 265

13 Weckhuysen, B.M. and Schoonheydt, R.A. Zeolites 1994 14, 360

14 Flanigen, E.M., Lok, B.M.T., Patton, R.L. and Wilson, S.T. Eur. Pat. 0158976 (1985)

15 Mabbs, F.E. and Collison, D. Electron Paramagnetic Resonance of Transition Metal Complexes, Elsevier, Amsterdam, 1992

16 Lever, A.P.P. Electronic Absorption Spectroscopy of Transition Metal lons, Elsevier, Amsterdam, 1982 
17 Wilson, S.T., Lok, B.M., Messina, C.A. and Flanigen, E.M. Proceedings of the Sixth International Zeolite Conference, Reno, 1983, p. 97

18 Bennet, J.M., Dytrych, W.J., Pluth, J.J., Richardson, J.W. and Smith, J.V. Zeolites 1986, 6, 349

19 Ballhausen, C.S. and Gray, H.B. Inorg. Chem. 1962, 1, 111

20 Ballhausen, C.S. and Gray, H.B. Introduction to Ligand Field Theory, W.A. Benjamin, Inc., New York, 1965, p. 228

21 Kucherov, A.V. and Slinkin, A.A. Zeolites 1987, 7, 583

22 Centi, G., Perathorer, S., Trifiro, F., Aboukais, A., Aissi, C.F. and Gueiton, M. J. Phys. Chem. 1992, 96, 2617

23 Petras, M. and Wichterlova, B. J. Phys. Chem. 1992, 96, 1805
24 Sass, C.E., Chen, X. and Kevan, L. J. Chem. Soc. Faraday Trans. 1990, 86, 189

25 Fejes, P., Marsi, I., Kiricsi, I., Halasz, J., Hannus, J., Rockenbauer, A., Tasi, G., Korecz, L. and Schöbel, G. Stud. Surf. Sci. Catal. 1991, 69, 173

26 Eon, J.G., Olier, R. and Volta, J.C. J. Catal. 1994, 145, 318

27 Kantcheva, M., Davydov, A. and Hadjivanov, K. J. Mol. Catal. 1993, 81, L25

28 Weckhuysen, B.M., Schoonheydt, R.A., Hu, H., Deo, G. and Wachs, I.E. Proceedings of the 14th North American Meeting of the Catalysis Society, Salt Lake City, 1995, in press 